Diabetologia (1994) 37: 10-14

\title{
Aminoguanidine reduces regional albumin clearance but not urinary albumin excretion in streptozotocin-diabetic rats
}

\author{
M.S. P. Huijberts ${ }^{1}$, B.H. R. Wolffenbuttel ${ }^{1}$, F. R. L. Crijns ${ }^{1}$, A.C. Nieuwenhuijzen Kruseman ${ }^{1}$, \\ M.H. A. Bemelmans ${ }^{2}$, H. A.J.Struijker Boudier ${ }^{3}$ \\ ${ }^{1}$ Department of Internal Medicine, Division of Endocrinology, University Hospital Maastricht, Maastricht, The Netherlands \\ ${ }^{2}$ Department of Surgery, University of Limburg, Maastricht, The Netherlands \\ ${ }^{3}$ Department of Pharmacology, University of Limburg, Maastricht, The Netherlands
}

Summary Advanced glycation end-product-formation is thought to play a role in the development of diabetic angiopathy. By altering the structure of different extracellular matrix components advanced glycation endproducts might affect vascular and glomerular permeability. In this study we investigated the effect of treatment with an inhibitor of advanced glycation endproduct-formation, aminoguanidine, on vascular permeability and the development of albuminuria in streptozotocin-induced diabetic rats. Male Wistar Rp rats were randomized into a control group, a diabetic group, and an aminoguanidine-treated diabetic group. After 8 weeks, 24-h urine collections were taken and rats were implanted with an arterial and a venous catheter. Mean arterial blood pressure was determined by intra-arterial measurement. Regional albumin clearances were assessed in the eye, ileum, lung, skeletal muscle and skin using an isotope technique. Mean arterial pressure in the diabetic group was significantly lower in the control and aminoguanidine-treated groups $(p<0.02)$. Regional albumin clearances were significantly increased in all tissues of diabetic rats compared to control rats $(p<0.05)$. Aminoguanidine treatment of diabetic rats resulted in a significant decrease of regional albumin clearance in all tissues except the lung ( $p<0.05$, lung $p=0.07$ ). The development of albuminuria in diabetic rats however, was not affected by aminoguanidine. [Diabetologia (1994) 37: 10-14]

Key words Diabetes mellitus, rat, advanced glycation end-products, aminoguanidine, vascular permeability, albuminuria.
The formation of advanced glycation end-products (AGEs) on long-lived macromolecules has been implicated in the aetiology of diabetic angiopathy. Numerous reports have shown that AGE-formation can alter the function of several systems that are involved in cardiovascular homeostasis [1].

Extracellular matrix components such as type IV collagen and laminin undergo marked structural changes following glycation $[2,3]$. The observed alterations might influence the interaction of these components with other basement membrane elements such as

Received: 26 February 1993

and in revised form: 8 July 1993

Corresponding author: Dr. M. Huijberts, Department of Internal Medicine, Division of Endocrinology and Metabolism, University Hospital Maastricht, P.O. Box 5800, NL-6202 AZ Maastricht, The Netherlands heparan sulphate proteoglycan (HS-PG). Alterations in the density of HS-PG in glomerular basement membrane and the vascular wall are thought to play a role in the development of both glomerular and systemic permeability changes in diabetes $[4,5]$. Increases in vascular permeability and increase in urinary albumin excretion have been shown to develop simultaneously in both clinical and experimental diabetes [6-9].

Aminoguanidine, a nucleophilic hydrazine compound, prevents the formation of AGEs [10]. This drug has been shown to decrease albuminuria in spontaneously hypertensive diabetic rats [11]. In addition, experiments in a skin-chamber model suggest that it can reduce the increased vascular permeability induced by hyperglycaemia [12]. We hypothesized that a beneficial effect of aminoguanidine would also imply reduction of increased regional albumin clearance in other organs. Therefore, in this study we assessed the effects of aminoguanidine treatment on blood pressure, albuminuria 
Table 1. General characteristics of the study groups

\begin{tabular}{|c|c|c|c|c|}
\hline & & $\begin{array}{l}\text { Body weight } \\
(\mathrm{g})\end{array}$ & $\begin{array}{l}\text { Blood glucose } \\
(\mathrm{mmol} / \mathrm{l})\end{array}$ & $\begin{array}{l}\text { Mean arterial pressure } \\
(\mathrm{mm} \mathrm{Hg})\end{array}$ \\
\hline Control & $\begin{array}{l}1 \\
2\end{array}$ & $\begin{array}{l}309 \pm 12 \\
297 \pm 8\end{array}$ & $\begin{array}{l}6.0 \pm 2.5 \\
6.5 \pm 1.5\end{array}$ & $\begin{array}{l}110 \pm 6 \\
115 \pm 4\end{array}$ \\
\hline Diabetes & $\begin{array}{l}1 \\
2\end{array}$ & $\begin{array}{l}223 \pm 34^{b} \\
205 \pm 29^{b}\end{array}$ & $\begin{array}{l}16.5 \pm 2.5^{b} \\
20.5 \pm 2.8^{b}\end{array}$ & $\begin{array}{l}100 \pm 5^{a} \\
102 \pm 5^{a}\end{array}$ \\
\hline $\begin{array}{l}\text { Diabetes }+ \\
\text { Aminoguanidine }\end{array}$ & $\begin{array}{l}1 \\
2\end{array}$ & $\begin{array}{l}225 \pm 25^{\mathrm{b}} \\
198 \pm 27^{\mathrm{b}}\end{array}$ & $\begin{array}{l}18.2 \pm 2.9^{\mathrm{b}} \\
19.3 \pm 3.1^{\mathrm{b}}\end{array}$ & $\begin{array}{l}109 \pm 5 \\
115 \pm 6\end{array}$ \\
\hline
\end{tabular}

a Significantly different from values in control rats, $p<0.02$;

${ }^{\mathrm{b}}$ Significantly different from values in control rats, $p<0.0001$.

and the permeability of various vascular beds, by measuring regional albumin clearances in diabetic rats. In previous studies we and others have shown that 8 weeks of experimental diabetes is sufficient for rats to develop serious vascular dysfunction, which closely resembles the disturbances observed in human diabetes $[8,13-15]$. Moreover, this diabetes duration is characterized by significant accumulation of AGEs [16].

\section{Materials and methods}

\section{Animals}

Male Wistar Rp rats (TNO-REPGO, Rijswijk, The Netherlands) were used. Rats were randomized into a control group $(n=8)$, a diabetic group $(n=8)$ and an aminoguanidine-treated diabetic group $(n=8)$. Diabetes was induced at the age of $6-$ 8 weeks by i.p. injection of $70 \mathrm{mg} / \mathrm{kg}$ streptozotocin (Sigma, St. Louis, Mo., USA) in citrate buffer ( $\mathrm{pH} 4.5$ ). Control rats received an i.p. injection of the vehicle. Development of diabetes was verified by blood glucose measurements (hexokinase method), 3 days after streptozotocin administration. Only rats with blood glucose levels above $15 \mathrm{mmol} / \mathrm{l}$ were included in the study. Aminoguanidine-hemisulphate (Sigma) was administered in daily doses of $50 \mathrm{mg} / \mathrm{kg}$ by s.c. injection. Treatment was started immediately after diabetes induction and continued for a period of 7 weeks. Urinary albumin excretion was measured in the original group of 24 rats and in an additional 18 rats, randomized and treated as described above.

\section{Surgery}

Two days prior to the extravasation study rats were anaesthetized with ether, and a polyethylene (PE-10)/vinyl catheter was implanted into the abdominal aorta through the left femoral artery. The caval vein was cannulated with a similar catheter through the left femoral vein. Both catheters were filled with saline, closed with metal plugs and exteriorized in the neck. The procedure was performed under aseptic conditions.

\section{Blood pressure measurements}

Since it has been shown that blood pressure data obtained with the indirect tail-cuff method are unreliable and artificially elevated in diabetic rats $[17,18]$, blood pressure was measured di-
1, Original group of $24(3 \times 8)$ rats;

2 , Additional batch of $18(3 \times 6)$ rats rectly in this study. One day after surgery, the arterial catheter was connected to a low volume displacement pressure transducer (CP-01, Century Technology Company, Inglewood, Calif., USA). The signal was recorded on a Grass 7D polygraph (Grass Instruments, Quincy, Mass., USA). Low-pass filtering of the signal yielded mean arterial pressure. During the measurements rats were allowed to move freely in their cages. Actual blood pressure measurements were performed following a 30 -min stabilization period.

\section{Determination of urinary albumin excretion}

Three days before the extravasation study, rats were placed in metabolic cages in order to collect $24-\mathrm{h}$ urine samples. Urinary production was determined and urine samples were frozen until further analysis (within 1 week). Urinary albumin content was measured by rocket immunoelectrophoresis [19] using a goat anti-rat albumin antibody (Nordic Immunological Laboratories, Tilburg, The Netherlands). The urine samples (diluted 1:5 or 1:10) and a rat albumin standard (Nordic) were added in $2 \mu l$ quantities to agarose gel plates containing $1 \%$ antibody. Rocket heights were measured and compared with the standard curve. The lowest detection limit of the assay was $5 \mu \mathrm{g} / \mathrm{ml}$.

\section{Determination of regional albumin permeation}

Regional albumin permeation was determined in the eye, ileum, skin, forearm skeletal muscle and lung using a double label isotope technique. We used a slightly modified version of previously published methods [20-22]. In brief, $0.128 \mathrm{MBq}$ ${ }^{125}$ I] human serum albumin ([$\left.{ }^{125} \mathrm{I}\right] \mathrm{HSA}$, CIS bio international, Gif-sur-Yvette, France) in a volume of $100 \mu \mathrm{l}$ was injected through the venous catheter at $t=0$. A $200 \mu \mathrm{l}$ arterial sample was taken $10 \mathrm{~min}$ later, and immediately afterwards $0.099 \mathrm{MBq}$ $\left[{ }^{131}\right.$ I]HSA (CIS bio international) was injected in a volume of $100 \mu \mathrm{l}$. After $2 \mathrm{~min}$, a second arterial sample was taken and rats were subsequently killed by injection of pentobarbital. Organs were excised immediately, blotted dry and weighed. Radioactivity of tissue and plasma samples was measured on a gammacounter (1282 Compugamma, Wallac LKB/Pharmacia, Woerden, The Netherlands) programmed for simultaneous determination of ${ }^{125} \mathrm{I}$ and ${ }^{131} \mathrm{I}$. Counts were corrected for background and crosstalk. Using this method, ${ }^{125}$ I]HSA is considered as the permeating tracer while $\left[{ }^{131} \mathrm{I}\right]$ HSA is used as marker for the intravascular space. The circulation time of $10 \mathrm{~min}$ for the permeating tracer has been shown to be sufficient to obtain a significant albumin extravasation, as albumin disappearance consists of two phases, a rapid one from $0-10 \mathrm{~min}$ after injection and a slower one from $10-60 \mathrm{~min}$, both accounting for $50 \%$ of the albumin ef- 


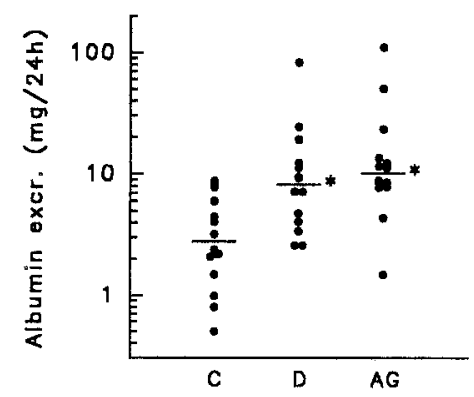

Fig. 1. Urinary albumin excretion rate $\left(\mathrm{U}_{\mathrm{alb}} \mathrm{V}\right) 8$ weeks after start of the study in control rats $(\mathrm{C}, n=14)$, diabetic rats (D, $n=14)$ and amino guanidine-treated diabetic rats ( $\mathrm{AG}, n=14)$. Individual $\mathrm{U}_{\mathrm{alb}} \mathrm{V}$ values are given plus the median value for each group. Significantly different from values in control rats, $* p<0.01$

flux per h $[23,24]$. In previous studies, both phases of albumin disappearance were shown to be increased in diabetic rats [25].

The amount of extravascular $\left[{ }^{125} \mathrm{I}\right] \mathrm{HSA}\left(\left[{ }^{125} \mathrm{~T}\right] \mathrm{HSA}_{\text {extra }}\right)$ could be calculated as:

$$
\begin{aligned}
& {\left[{ }^{125} \mathrm{I}\right] \mathrm{HSA}_{\text {extra }}=} \\
& {\left[{ }^{125} \mathrm{I}\right] \mathrm{HSA}_{\text {tissue }}-\frac{\left[{ }^{125} \mathrm{I}\right] \mathrm{HSA}_{\text {plasma, } \mathrm{t}=12}}{\left[{ }^{131} \mathrm{I}\right] \mathrm{HSA}_{\text {plasma } \mathrm{t}=12}} \times\left[{ }^{131} \mathrm{I}\right] \mathrm{HSA}_{\mathrm{tissue}}}
\end{aligned}
$$

where $\left[{ }^{125} I\right] H S A_{\text {tissue }}$ and $\left[{ }^{131} I\right] H S A_{\text {tissue }}$ represent the amount of radioactive material in tissue 12 min after the start of the experiment and $\left[{ }^{125} \mathrm{I}\right] \mathrm{HS} \mathrm{A}_{\text {plasma, } t=12}$ and $\left[{ }^{131} \mathrm{I}\right] \mathrm{HS} \mathrm{A}_{\text {plasma, } t=12}$ represent radioactivity in plasma at $12 \mathrm{~min}$.

Clearance was calculated per tissue from extravascular $\left[{ }^{125} \mathrm{I}\right] \mathrm{HSA}$ and the area under the time concentration curve (AUC) for $\left.{ }^{125} \mathrm{I}\right] \mathrm{HSA}$ in plasma from $0-12 \mathrm{~min}$, using standard pharmacokinetic methods, assuming log-linear disappearance of albumin from plasma [22].

Clearance $=\frac{\left[{ }^{125} \mathrm{I}\right] \mathrm{HSA}_{\text {extra }}}{\mathrm{AUC}\left[{ }^{125} \mathrm{I}\right] \mathrm{HSA}_{\text {plasma }}}$

Clearances were normalized for tissue weight and expressed as $\mu \mathrm{l} \cdot \mathrm{g}$ tissue ${ }^{-1} \cdot \min ^{-1}$.

\section{Statistical analysis}

All values are given as mean $\pm S D$, or as median with range when not normally distributed. Groups were compared with analysis of variance (ANOVA) with the Sidak post-hoc test for multiple comparisons or with the Kruskal Wallis test when not normally distributed (Crunch4 Manual, Crunch Software Corporation, Oakland, Calif., USA).

\section{Results}

\section{General characteristics}

Body weight was lower in both groups of diabetic rats compared to control rats $(p<0.0001)$, while blood glu$c o s e$ levels were significantly elevated in the diabetic groups $(p<0.0001$, Table 1$)$. Between untreated diabetic rats and aminoguanidine-treated rats neither dif-
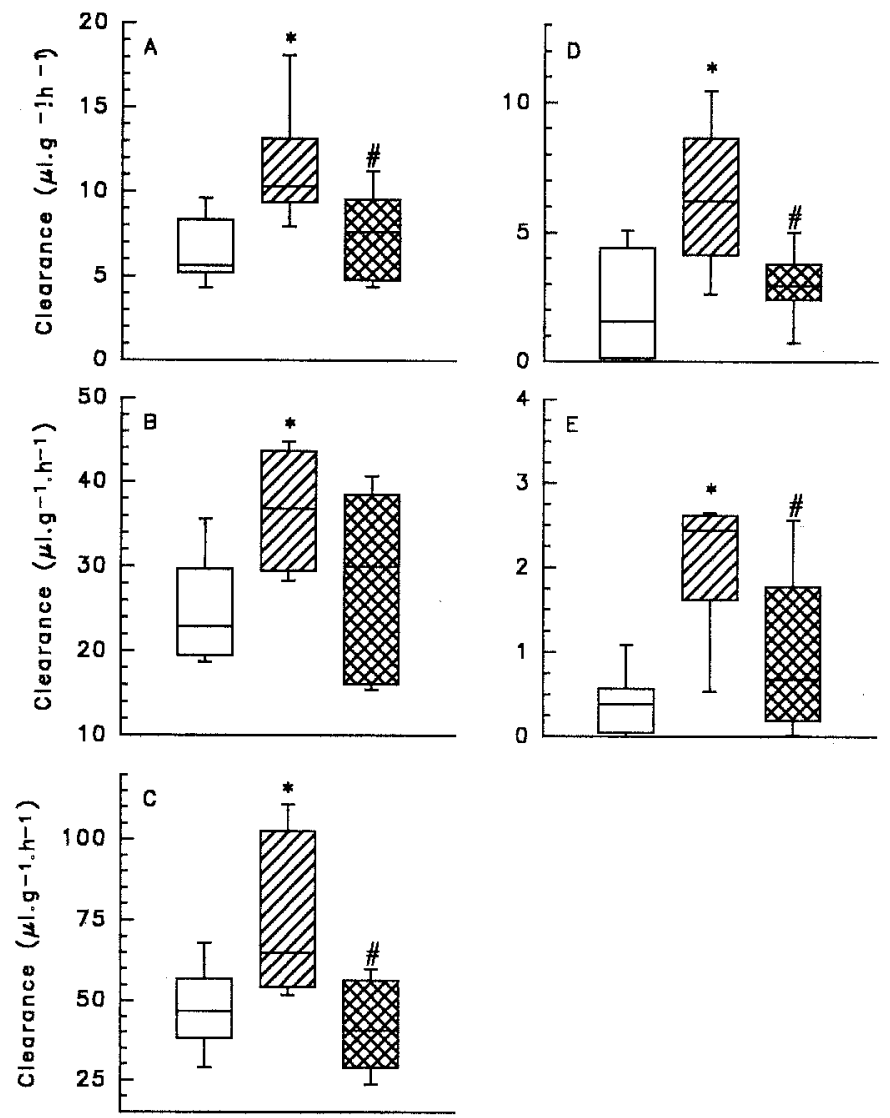

Fig.2 A-E. Regional albumin clearances in the eye (A), lung (B), ileum (C), skin (D) and skeletal muscle (E) of control rats $(\square)$, diabetic rats ( $\square$ ) and aminoguanidine-treated diabetic rats ( $\varangle$ ). Box plots represent median, interquartile range and 5th and 95 th percentiles. * significantly different from control values, $p<0.05$, \# significantly different from values in diabetic rats, $p<0.05$

ferences in body weight nor blood glucose levels could be observed. Body weight and blood glucose levels of the additional 18 rats that were used to determine urinary albumin excretion are also given in Table 1.

\section{Blood pressure}

Mean arterial blood pressure was significantly lower in diabetic rats compared to control rats $(p<0.02$, Table 1), while rats treated with aminoguanidine had mean arterial pressures comparable to those of control rats.

\section{Urinary albumin excretion}

Urinary albumin excretion rate $\left(\mathrm{U}_{\text {alb }} \mathrm{V}\right)$ was significantly elevated in diabetic rats compared to control rats, although there was a large variation in the values of $\mathrm{U}_{\mathrm{alb}} \mathrm{V}$ in diabetic rats (median $8.3 \mathrm{mg} / 24 \mathrm{~h}$, range [2.6-84.1] in diabetic rats vs $2.8 \mathrm{mg} / 24 \mathrm{~h}$ range [0.5-8.8] in control rats, $p<0.01$, Fig. 1). Aminoguanidine treatment did not affect $U_{a l b} V$ in diabetic rats. In the aminoguanidine- 
treated group, the variation in $\mathrm{U}_{\mathrm{alb}} \mathrm{V}$ values was comparable to that of untreated diabetic rats (median 10.1 $[1.5-112.7], p<0.001$ compared to control rats).

\section{Effects on regional albumin permeation}

In all organs regional albumin clearance was significantly increased in diabetic rats compared to control rats (Fig.2). Diabetic rats treated with aminoguanidine had albumin clearances that were significantly lower than those of untreated rats and not different from values of control rats in all tissues, except the lung ( $p=0.07$ compared to diabetic rats).

\section{Discussion}

This study reveals a marked effect of long-term treatment with aminoguanidine, an inhibitor of AGE-formation, on increased regional albumin clearance in diabetic rats. However, no effects on urinary albumin excretion were observed. In addition we found a slight blood pressure elevating effect of aminoguanidine.

The observed effects of aminoguanidine on regional albumin clearance are in accordance with the report of Corbett et al. [12] who showed a normalization of permeability induced by hyperglycaemia in skin-chamber granulation tissue. They suggest that aminoguanidine normalizes increased vascular permeability by correcting the diabetes induced nitric oxide (NO)-overproduction leading to increased flow, since other inhibitors of NO-formation such as $\mathrm{N}^{\mathrm{G}}$-Monomethyl-L-arginine ( $\mathrm{L}$ NMMA) had similar effects. In their study aminoguanidine administration also slightly raised blood pressure, although about 40 times less effectively than LNMMA. Very recently, Tilton et al. [26] showed that methylguanidine, a compound with a comparable NOsynthase inhibiting action as aminoguanidine but no effects on AGE-formation, also prevented vascular dysfunction in experimental diabetes. However, we measured increases in vascular permeability in vascular beds, such as skeletal muscle and skin, to which blood flow is decreased in experimental diabetes [27], which makes the concept of NO-overproduction resulting in increased flow and increased vascular permeability, not generally applicable. In addition, in another study we have observed a significant increase in vascular elasticity in diabetic rats following long-term treatment with aminoguanidine which could not be attributed to NOdependent alterations in vascular tone [28], indicating that there are beneficial effects of aminoguanidine on vascular dysfunction in diabetes that are definitely not related to its NO-inhibiting actions. Since we have not quantified effects of aminoguanidine treatment in nondiabetic rats, the possibility that aminoguanidine reduces albumin clearance per se, whether increased or not cannot be ruled out. On the other hand, Kihara et al. [29] have shown that aminoguanidine treatment did not affect the unaltered albumin clearance of sciatic nerve tissue from diabetic rats.

Increased urinary albumin excretion was not affected by aminoguanidine in this study. This is in contrast to the results in spontaneously hypertensivediabetic rats [11] and in diabetic rats [30]. In both studies rats were treated for a significantly longer period (24-32 weeks) which might explain the difference between our results and these studies. In addition, one study does not report effects on blood pressure [30] whereas the other refers to blood pressures that were determined by indirect tail-cuff plethysmography, and therefore cannot be interpreted properly. There is strong evidence that this method produces artificially elevated blood pressure recordings, as a result of either structural or haemodynamic alterations in the tail of diabetic rats $[17,18]$. In our own laboratory we also observed differences between direct intra-arterial blood pressure measurements and tail-cuff recordings. Taking into account the observed rise in mean arterial pressure following aminoguanidine treatment, one could speculate that effects on urinary albumin excretion are masked by an increase in blood pressure, although we did not find any relationship between blood pressure and albuminuria in our animals. Urinary albumin excretion is certainly influenced by arterial pressure as has been demonstrated by the marked effects of different antihypertensive regimens on urinary albumin excretion in both experimental and clinical diabetes [31, 32].

The observed disparity in effects of aminoguanidine on regional albumin clearance and urinary albumin excretion might also indicate that the mechanisms involved in the development of systemic permeability changes and albuminuria are, at least partially, distinct. The fact that increased vascular permeability, assessed by measuring the transcapillary escape rate of albumin, only develops in diabetic patients with some degree of albuminuria [6] together with the tremendous increase in cardiovascular disease that is associated with the development of albuminuria [33], has led to the hypothesis that albuminuria is a marker of widespread vascular damage [7]. A decreased content of HS-PG, as a result of AGE-formation on basement membrane components [1] or a genetically determined defect in HS-PG regulation [34], has been proposed as one of the mechanisms responsible for both vascular and glomerular damage. Using our results, one can only speculate as to why and how aminoguanidine normalizes increased vascular permeability in diabetic rats without affecting albuminuria. However, in our opinion, in the kidney, haemodynamic changes which are perhaps not modified by aminoguanidine, play a more important role than in other tissues. It is important in this respect to remember that glomerular capillary pressure is several times higher than capillary pressures in other tissues. In previous studies it has been shown that the albuminuria in experimental diabetes is particularly sensitive to angiotensin converting enzyme-inhibitors 
$[13,31]$. This would support the concept that angiotensin II-dependent intrarenal haemodynamic mechanisms contribute to the control of urinary albumin excretion.

In conclusion, we have shown that aminoguanidine treatment normalizes increased vascular permeability in diabetic rats, while in this study no effects of aminoguanidine on albuminuria were observed. The effects of aminoguanidine on vessel wall permeability suggest that this drug can protect the vascular system in (experimental) diabetes.

Acknowledgements. The authors wish to thank Dr. Ir. P.P.C. A. Menheere for his advice on the isotope measurements.

\section{References}

1. Brownlee M (1992) Glycation products and the pathogenesis of diabetic complications. Diabetes Care 15: 1835-1843

2. Tsilbary EC, Charonis AS, Reger LA, Wohlhueter RM, Furcht LT (1988) The effect of non-enzymatic glycosylation on the binding of the main non-collagenous NCl domain to type IV collagen. J Biol Chem 263: 4302-4308

3. Charonis AS, Reger LA, Dege JE et al. (1990) Laminin alterations after in vitro non-enzymatic glycosylation. Diabetes 39: 807-814

4. Shimomura H, Spiro RG (1987) Studies on macromolecular components of human glomerular basement membrane and alterations in diabetes: decreased levels of heparan sulfate proteoglycan and laminin. Diabetes 36: 374-381

5. Wu V-Y, Wilson B, Cohen MP (1987) Disturbances in glomerular basement membrane glycosaminoglycans in experimental diabetes. Diabetes 36: 679-683

6. Feldt-Rasmussen B (1986) Increased transcapillary escape rate of albumin in type 1 (insulin-dependent) diabetic patients with microalbuminuria. Diabetologia: 29:282-286

7. Deckert T, Feldt-Rasmussen B, Borch-Johnsen K, KofoedEnevoldsen A (1989) Albuminuria reflects widespread vascular damage: the Steno hypothesis. Diabetologia 32: 219-226

8. Williamson JR, Chang K, Tilton RG et al. (1987) Increased vascular permeability in spontaneously diabetic $\mathrm{BB} / \mathrm{W}$ rats and in rats with mild versus severe streptozotocin-induced diabetes. Prevention by aldose reductase inhibitors and castration. Diabetes 36: 813-821

9. Tucker BJ, Blantz RC, Rasch R (1992) Glomerular filtration and tubular reabsorption of albumin in early and established STZ-diabetic rats. Diabetologia 35: A11 (Abstract)

10. Thomas G, Ramwell PW (1991) Effects of guanodino compounds on the endothelium-derived relaxing factor inhibitor NG-monomethyl L-arginine. J Pharmacol Exp Ther 259: 490-494

11. Edelstein D, Brownlee M (1992) Aminoguanidine ameliorates albuminuria in diabetic hypertensive rats. Diabetologia 35: 96-97

12. Corbett JA, Tilton RG, Chang K et al. (1992) Aminoguanidine, a novel inhibitor of nitric oxide formation, prevents diabetic vascular dysfunction. Diabetes 41: 552-556

13. Huijberts MSP, Wolffenbuttel BHR, Crijns FRL et al. (1993) Angiotensin converting enzyme-inhibition reduces urinary albumin excretion but not regional albumin clearance in experimental diabetes. Eur J Pharmacol 240: 207-212

14. Bucala R, Tracey KJ, Cerami A (1991) Advanced glycosylation products quench nitric oxide and mediate defective en- dothelium-dependent vasodilatation in experimental diabetes. J Clin Invest 87: 432-438

15. Tilton RG, Chang KG, Pugliese G et al. (1989) Prevention of hemodynamic and vascular albumin filtration changes in diabetic rats by aldose reductase inhibitors. Diabetes 38 : $1258-1270$

16. Makita Z, Vlassara H, Cerami A, Bucala R (1992) Immunological detection of advanced glycosylation endproducts in vivo. J Biol Chem 267: 5133-5138

17. Kusaka M, Kishi K, Sokabe H (1987) Does so-called streptozotocin hypertension exists in rats? Hypertension 10: $517-521$

18. Tomlinson KC, Gardiner SM, Bennett T (1990) Blood pressure in streptozotocin-treated Brattleboro and Long Evans rats. Am J Physiol 258: R852-R859

19. Laurell C-B (1972) Electroimmunoassay. Scand J Lab Clin Invest 29 [Suppl 124]: 21

20. Pugliese G, Tilton RG, Speedy A et al. (1990) Modulation of hemodynamic and vascular filtration changes in diabetic rats by dietary myo-inositol. Diabetes 39: 312-322

21. Williamson JR, Holmberg SW, Chang KG, Marvel J, Sutera S, Needleman P (1989) Mechanisms underlying atriopeptininduced increases in hematocrit and vascular permeation in rats. Circ Res 64: 890-899

22. de Vries PJF, Tyssen C, Struijker Boudier HAJ, Smits JFM (1990) Atrial natriuretic factor increases albumin extravasation in conscious rats. Eur J Physiol 415: 507-509

23. Bent-Hansen L (1991) Whole body capillary exchange of albumin. Acta Physiol Scand 143: 5-10

24. Bent-Hansen L (1991) Initial plasma disappearance and tissue uptake of 131I-albumin in normal rabbits. Microvasc Res 41: 345-356

25. Tucker BJ (1990) Early onset of increased transcapillary escape rate in awake diabetic rats. Diabetes 39:919-923

26. Tilton RG, Chang K, Hasan KS et al. (1993) Prevention of vascular dysfunction by guanidines. Inhibition of nitric oxide synthase versus advanced glycation end-product formation. Diabetes 42: 221-232

27. Hill MA, Larkins RG (1989) Alterations in the distribution of cardiac output in experimental diabetes in rats. Am J Physiol 257: H571-H580

28. Huijberts MSP, Wolffenbuttel BHR, Struijker Boudier HAJ et al. (1993) Aminoguanidine treatment increases elasticity and decreases fluid filtration of large arteries from diabetic rats. J Clin Invest 92: 1407--1411

29. Kihara M, Schmelzer JD, Poduslo JF, Curran GL, Nickander KK, Low PA (1991) Aminoguanidine effects on nerve blood flow, vascular permeability, electrophysiology, and oxygen free radicals. Proc Natl Acad Sci USA 88: 6107-6111

30. Soulis-Liparota T, Cooper M, Papazoglou D, Clarke B, Jerums J (1991) Retardation by aminoguanidine of development of albuminuria, mesangial expansion, and tissue fluorescence in streptozotocin-induced diabetic rat. Diabetes 40: $1328-1334$

31. Anderson S, Rennke HG, Garcia DL, Brenner BM (1989) Short and long term effects of antihypertensive therapy in the diabetic rat. Kidney Int 36: 526

32. Parving H-H, Andersen AR, Schmidt UM, Hommel E, Mathiesen ER, Svendsen PA (1987) Effect of anti-hypertensive treatment on kidney function in diabetic nephropathy. BMJ 294: 1443-1445

33. Borch-Johnsen K, Kreiner S (1987) Proteinuria - A predictor of cardiovascular mortality in insulin-dependent diabetes mellitus. BMJ 294: 1651-1654

34. Deckert TD, Kofoed-Enevoldsen A, Norgaard K, BorchJohnsen K, Feldt-Rasmussen B, Jensen T (1992) Microalbuminuria. Implications for micro- and macrovascular disease. Diabetes Care 15: 1181-1191 